\title{
Fabrication and characteristics of HTS induction motor by the use of Bi-2223/Ag squirrel-cage rotor
}

$\operatorname{AUTHOR}(S)$ :

Nakamura, T; Miyake, H; Ogama, Y; Morita, G; Muta, I; Hoshino, T

\section{CITATION:}

Nakamura, T ... [et al]. Fabrication and characteristics of HTS induction motor by the use of Bi-2223/Ag squirrel-cage rotor. IEEE TRANSACTIONS ON APPLIED

SUPERCONDUCTIVITY 2006, 16(2): 1469-1472

ISSUE DATE:

2006-06

URL:

http://hdl.handle.net/2433/50176

\section{RIGHT:}

(c)2006 IEEE. Personal use of this material is permitted. However, permission to reprint/republish this material for advertising or promotional purposes or for creating new collective works for resale or redistribution to servers or lists, or to reuse any copyrighted component of this work in other works must be obtained from the IEEE. 


\title{
Fabrication and Characteristics of HTS Induction Motor by the Use of Bi-2223/Ag Squirrel-Cage Rotor
}

\author{
Taketsune Nakamura, Hironori Miyake, Yoshio Ogama, Gaku Morita, Itsuya Muta, and Tsutomu Hoshino
}

\begin{abstract}
HTS squirrel-cage induction motor was fabricated and tested in this study. Both of rotor bars and end rings were made of Bi-2223/Ag multifilamentary tapes in order to realize superconducting current loops, and the conventional (normal conducting) stator, 3-phase and 4-pole, was utilized. Rotating characteristics of the fabricated motor were tested for different input voltages at $60 \mathrm{~Hz}$. The performances were also analyzed by means of the theoretical method based on the electrical equivalent circuit. It was shown that the minimum starting voltage was experimentally confirmed and agreed semi-quantitatively with the analysis result. The rotation at synchronous speed was realized by applying the load, at least, $1.5 \mathrm{Nm}$.
\end{abstract}

Index Terms-Bi-2223/Ag multifilamentary tape, induction motor, minimum starting voltage, persistent current mode, synchronous torque.

\section{INTRODUCTION}

I NDUCTION motor is well known to be widely utilized in a capacity range from fractional horsepower to large capacity motors. For instance, all of the inverter fed motors for the electric trains are squirrel-cage type induction motors in Japan. On the other hand, advances in fabrication technology of high- $T_{\mathrm{c}}$ superconductor (HTS) have continuously stimulated the power application systems. As one of such applications, we have studied the HTS induction motor, which has HTS squirrelcage type windings.

Above-mentioned motor has already been developed and tested by Sim et al. [1], [2], and found that the synchronous torque exists. Their study, however, has not shown the detailed theoretical discussion for the mechanism of synchronism based on the material property of HTS conductors. With respect to such theoretical study, we have already developed the analysis code based upon the electrical equivalent circuit, and explain the mechanism of the performance [3].

In this study, we develop and test the HTS induction motor with the use of $\mathrm{Bi}-2223 / \mathrm{Ag}$ tape conductors as squirrel-cage rotor. We firstly concentrate upon the threshold voltage for the realization of flux flow state in the superconducting cage loops.

Manuscript received September 20, 2005. This work was supported in part by the 21st Century COE Program (No. 14213201) from The Ministry of Education, Culture, Sports, Science and Technology, Japan.

T. Nakamura, H. Miyake, and Y. Ogama are with the Kyoto University, Kyoto-Daigaku Katsura 1, Nishikyo-Ku, Kyoto 615-8510, Japan (e-mail: tk_naka@kuee.kyoto-u.ac.jp).

G. Morita is with the Railway Technical Research Institute, Hikari-Cho 2-8-38, Kokubunji 185-8540, Japan.

I. Muta is with the Saga University, Honjo-Cho 1, Saga 840-8502, Japan.

T. Hoshino is with the Meisei University, Hodokubo 2-1-1, Hino 191-8506, Japan.

Digital Object Identifier 10.1109/TASC.2005.864293
TABLE I

SPECIFICATIONS OF Bi-2223/Ag MULTIFILAMENTARY TAPES UTILIZED FOR THE SQUIRREL-CAGE ROTOR WINDINGS

\begin{tabular}{lll}
\hline \hline Item & Rotor bars & End rings \\
\hline Width $/ \mathrm{mm}$ & 2.0 & 4.3 \\
Thickness $/ \mathrm{mm}$ & 0.20 & 0.22 \\
Cross sectional area $/ \mathrm{mm}^{2}$ & 0.40 & 0.95 \\
Silver ratio & 2.0 & 2.2 \\
Critical current, $I_{\mathrm{c}} / \mathrm{A}$ & 25 & 90 \\
$(77.3 \mathrm{~K}$, self-field) & & \\
\hline \hline
\end{tabular}

This voltage is crucial for starting. And then, this voltage is compared with the value obtained from the equivalent circuit. Further, the rotating characteristics are investigated experimentally and discussed.

\section{FABRICATION AND TeST METHOD}

\section{A. Specifications of Bi-2223/Ag Tapes}

Both of rotor bars and end rings are fabricated by using Bi-2223/Ag multifilamentary tapes. The specifications, however, are different between them (Table I). That is, narrow width tape, i.e., $2.0 \mathrm{~mm}$, is utilized for rotor bars because of the restriction of the space in the rotor slot. Four tapes are connected in parallel by using solder, and this bundle is used for a rotor bar, i.e., its total critical current is $100 \mathrm{~A}(=25 \mathrm{~A} \times 4)$.

On the other hand, large current will be induced in the end rings compared to the rotor bars, and then the tape that has large critical current, $I_{\mathrm{C}}(=90 \mathrm{~A}$ at $77.3 \mathrm{~K}$ and self-field), is utilized for this purpose. Here, the HTS end rings are designed to be always in the superconducting state, i.e., the induced current will be less than $I_{\mathrm{c}}$. That is, the end rings consist of the $\mathrm{Bi}-2223 / \mathrm{Ag}$ windings at 6 turns, i.e., its total critical current is about $540 \mathrm{~A}$ $(=90 \mathrm{~A} \times 6)$.

\section{B. Characterization of Bi-2223/Ag Tape for Rotor Bars}

The performance of the induction motor is dominated by the characteristics of $\mathrm{Bi}-2223 / \mathrm{Ag}$ tapes utilized for the rotor bars. Therefore, electric field, $E$, vs. current density, $J,(E-J)$ curve for such tape is firstly characterized. It should be noted that the HTS rotor bars are placed in the slots of the rotor, which are made of laminated silicon steel cores. Then, almost all magnetic fluxes pass through this iron rotor, and the HTS rotor bars experience only self-field. In other words, we don't need to take account of the magnetic field dependency of current transport properties in Bi-2223/Ag tape, i.e., self-field application. Fig. 1 shows the double-logarithmic plot of $E-J$ curve of the tape for 


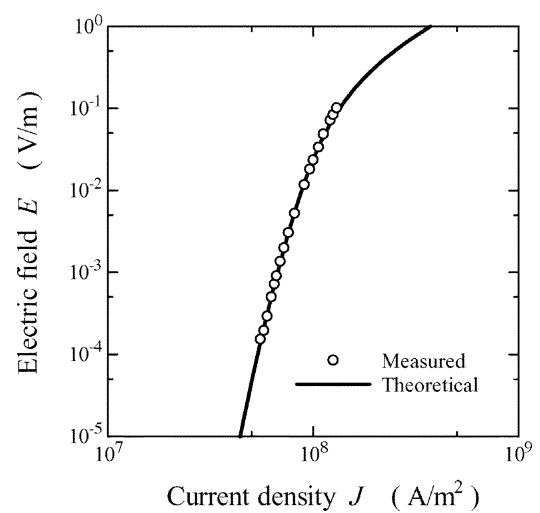

Fig. 1. Electric field, $E$, vs. current density, $J$, curve of Bi-2223/Ag tape utilized for rotor bars, at $77.3 \mathrm{~K}$ and self-field. Empty circles show the measured data, and solid curve the theoretical expression with (1)-(3).

rotor bars, measured at $77.3 \mathrm{~K}$ and self-field. In this figure, the empty circles denote measured data, and the solid curve shows the theoretical one (Weibull function), which is expressed as follows [4], [5]

$$
\begin{aligned}
& E(J)=\rho_{\mathrm{ff}} J_{0} \int_{0}^{\frac{J-J_{\mathrm{cm}}}{J_{0}}}\left[1-\exp \left(-j^{m}\right)\right] \mathrm{d} j, \quad J>J_{\mathrm{cm}} \\
& 0, \quad J \leq J_{\mathrm{cm}}
\end{aligned}
$$

where $J_{\mathrm{cm}}\left(=6.27 \times 10^{7} \mathrm{~A} / \mathrm{m}^{2}\right)$ and $J_{0}\left(=5.19 \times 10^{8} \mathrm{~A} / \mathrm{m}^{2}\right)$, respectively, denote the minimum and the half value of width of the local critical current density distribution. The parameter $\rho_{\mathrm{ff}}\left(=9.57 \times 10^{-8} \Omega \mathrm{m}\right)$ means the resistivity for uniform flux flow, and $m(=5.72)$ the shape of the critical current distribution. Further, the effect of the current sharing to the silver sheath is also considered, and the total current, $J_{\mathrm{tl}}$, is calculated by using the following relation

$$
J_{\mathrm{tl}}=\frac{1}{c+1} J+\frac{c}{c+1} \frac{E(J)}{\rho_{\mathrm{ag}}}
$$

where, the parameter $c(=2.0)$ and $\rho_{\mathrm{ag}}$, respectively, denote the silver ratio and the resistivity of silver sheath.

As can be seen in Fig. 1, the agreement between the experiment and the theory is excellent, and then (1)-(3) are introduced to the analysis of the motor performance based on the electrical equivalent circuit.

\section{HTS Rotor}

As is already mentioned, the HTS squirrel-cage windings are fabricated by using the laminated silicon steel rotor. In this study, the stator of the commercialized induction motor, 3-phase, 4-pole, $1.5 \mathrm{~kW}$, are utilized. In other words, the secondary windings are only replaced by HTS, and then the simple structure of the conventional induction motor is maintained. Fig. 2 illustrates the schematic diagram of the cross section of a rotor slot. As can be seen, the superconducting Bi-2223 rotor bar is put at the outermost surface of the rotor, i.e., near the air-gap, in order to reduce the effect of the leakage magnetic flux [3]. Insulated copper bars are also installed in the slot in

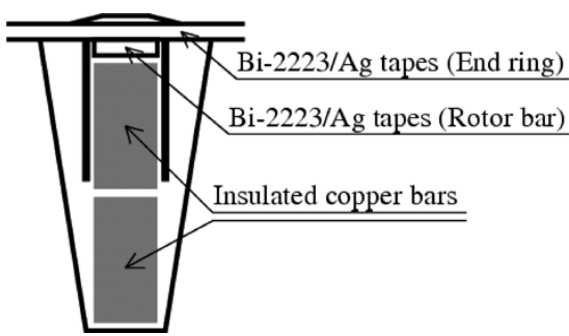

Fig. 2. Schematic diagram of a rotor slot with rotor bar and end ring.

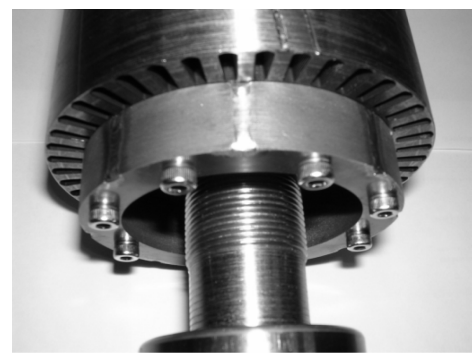

(a)

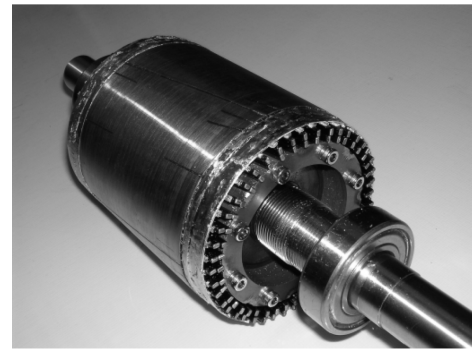

(b)

Fig. 3. Photographs of fabricated HTS squirrel-cage rotor. (a) Rotor core and slots; (b) completed HTS rotor.

order to support as well as cool the rotor bars. Bi-2223 end rings are connected with the above mentioned rotor bars by using the solder. Fig. 3 shows the photographs of (a) rotor core and slots and (b) completed HTS rotor, respectively.

\section{Test Method}

The fabricated motor is immersed in liquid nitrogen, and then the rotating characteristics are tested at no-load and light load conditions. Before the experiment, the lubricating oil of the roller bearings are removed by using acetone for avoidance of freezing. Then, the mechanical loss of the bearings are enlarged due to the friction. Rotating speed, $N$, and torque, $\tau$, are measured by means of torque/speed meter installed outside the cryostat (Fig. 4). The application of light load is also available by using the powder brake (its maximum value is $1.8 \mathrm{Nm}$ ). The driving frequency is fixed to be $60 \mathrm{~Hz}$, and then the corresponding synchronous speed, $N_{\mathrm{S}}$, is $1800 \mathrm{rpm}$.

\section{ANALYSIS METHOD}

Performance of the fabricated HTS induction motor is also investigated based upon the commonly utilized equivalent circuit as shown in Fig. 5. In these figures, $V_{1}$ means the input voltage (phase voltage). And $F^{\prime}\left(I_{2}^{\prime}\right) / s$ and $V_{2 \mathrm{~s}}^{\prime}$ denote the voltage of the secondary (HTS) windings at slip and synchronous operations, 


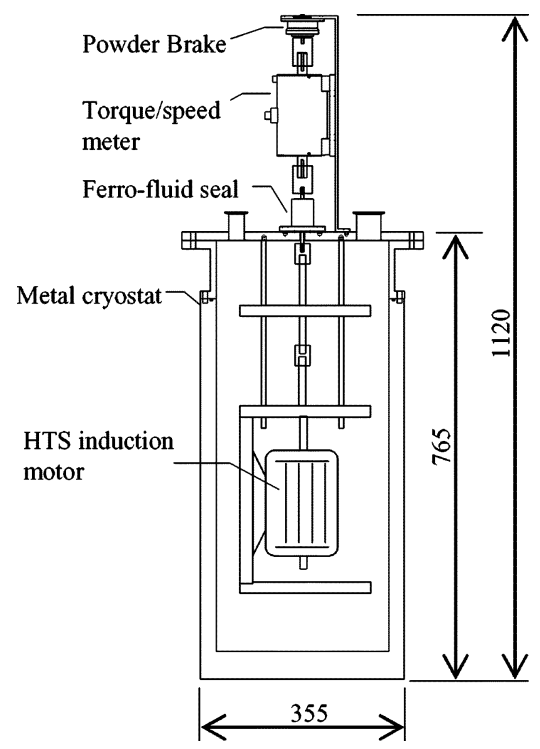

Fig. 4. Schematic diagram of test system. Fabricated HTS induction motor is installed in the metal cryostat, and immersed in liquid nitrogen.

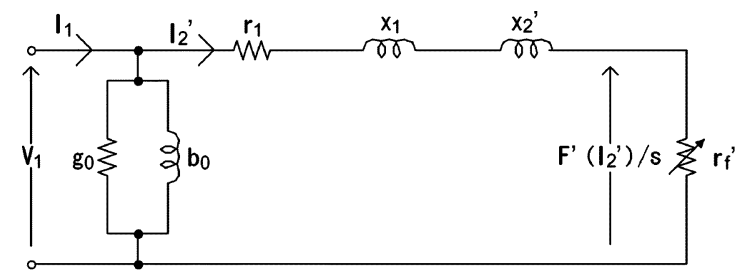

(a)

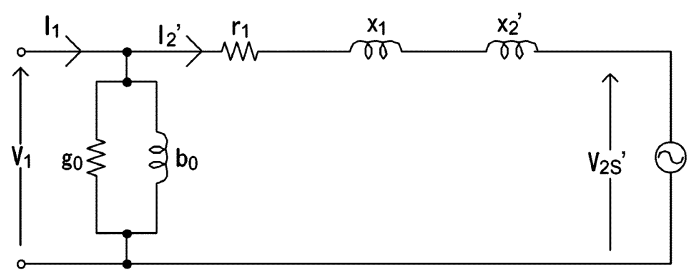

(b)

Fig. 5. Electrical equivalent circuit of HTS induction motor for one phase [3]. (a) Slip mode; (b) synchronous mode.

respectively. Here, slip, $s$, is defined as $s=\left(N_{\mathrm{s}}-N\right) / N_{\mathrm{s}}$. The parameters $g_{0}, b_{0}, r$, and $x$, correspondingly, denote the exciting conductance, exciting susceptance, resistance of the windings, and the leakage reactance. Further, the subscript 1 (or 2) shows the primary (or secondary) side, and the prime ' shows that the secondary parameter is converted into the primary side.

At slip mode [Fig. 5(a)], the nonlinear resistance, $r_{\mathrm{f}}^{\prime}\left(I_{2}^{\prime}\right)$, due to the flux flow is generated in the HTS rotor windings. In this case, the voltage, $F^{\prime}\left(I_{2}^{\prime}\right) / s\left(=r_{\mathrm{f}}^{\prime}\left(I_{2}^{\prime}\right) I_{2}^{\prime}\right)$, is calculated by using (1) and (3) (for detailed explanation, see [3] because of the lack of space). On the other hand, when the above-mentioned resistance becomes zero by accelerating, i.e., the corresponding slip frequency reduces, the persistent current mode will be realized. In that case, the interlinked magnetic fluxes will be trapped in the windings, and then the voltage source, $V_{2 \mathrm{~s}}^{\prime}$, equivalently appears at the secondary windings, i.e., synchronous mode [Fig. $5(b)$, see (5) for $V_{2 \mathrm{~s}}^{\prime}$.

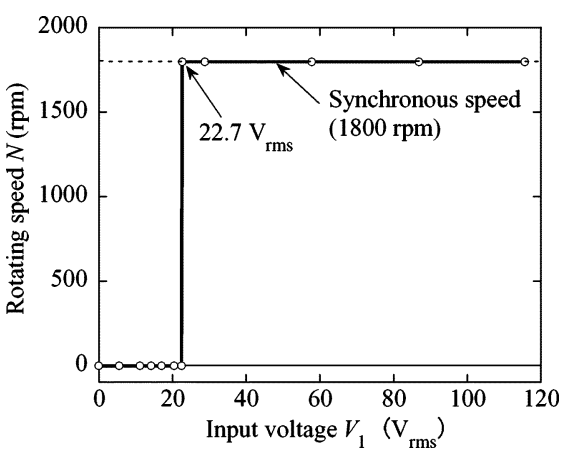

Fig. 6. Test results of rotating speed, $N$, vs. input voltage, $V_{1}$, characteristics in a no-load condition at $77.3 \mathrm{~K}$. Symbols are the measured data, and the solid curve is guided to the eyes.

\section{RESUlTS AND DisCUSSION}

\section{A. Minimum Voltage for Starting}

It has already been reported based on the analysis that there exists the minimum starting voltage for the HTS motor [3]. That is, the loops in the HTS squirrel-cage windings will initially be in the superconducting state. And then, we need the threshold voltage in order to make the superconducting loops be the dissipative state, i.e., flux-flow state. This voltage is essential for the generation of starting torque, and can be estimated in the following. That is, the voltage of the HTS squirrel-cage windings is expressed as follows [see Fig. 5(a)]

$$
\left|\frac{F^{\prime}\left(I_{2}^{\prime}\right)}{s}\right|=\sqrt{\left|V_{1}\right|^{2}-\left(x_{1}+x_{2}^{\prime}\right)^{2}\left|I_{2}\right|^{\prime 2}}-r_{1}\left|I_{2}^{\prime}\right|
$$

Then, the voltage for the synchronous mode [Fig. (5b)], $\left|V_{2 \mathrm{~s}}^{\prime}\right|$, can be calculated by using the relation, $\left|I_{2}^{\prime}\right|=\left|I_{\mathrm{c}}^{\prime}\right|$, as follows

$$
\left|V_{2 \mathrm{~s}}^{\prime}\right|=\lim _{I_{2}^{\prime} \rightarrow I_{\mathrm{c}}^{\prime}}\left|\frac{F^{\prime}\left(I_{2}^{\prime}\right)}{s}\right|
$$

where, the parameter, $\left|I_{\mathrm{c}}^{\prime}\right|$, is the critical current defined by the electric field criterion at $1 \mu \mathrm{V} / \mathrm{cm}$. Finally, the minimum starting voltage (phase voltage), $\left|V_{1 \mathrm{~s}}\right|$, is expressed by using (4) and (5) with the condition, $V_{2 \mathrm{~s}}^{\prime}=0$, as follows.

$$
\left|V_{1 \mathrm{~s}}\right|=\sqrt{r_{1}^{2}+\left(x_{1}+x_{2}^{\prime}\right)^{2}}\left|I_{\mathrm{c}}^{\prime}\right|
$$

Based on the experiment, the parameters, $r_{1},\left(x_{1}+x_{2}^{\prime}\right)$ and $\left|I_{\mathrm{c}}^{\prime}\right|$ are determined to be, $0.12 \Omega, 5 \Omega$ and 4 A, respectively. And then, the corresponding minimum starting voltage, $\left|V_{1 \mathrm{~s}}\right|$, is 18.5 $\mathrm{V}_{\text {rms. }}$.

On the other hand, this voltage is also confirmed by the experiment. That is, $\left|V_{1 s}\right|$ is defined by the voltage at which the HTS motor starts rotating, and estimated to be $22.7 \mathrm{~V}_{\text {rms }}$ (see Fig. 6). This value is semi-quantitatively consistent with that of the analysis result. The reasons for the difference between them are friction of the liquid nitrogen, mechanical loss of the roller bearing, etc. 


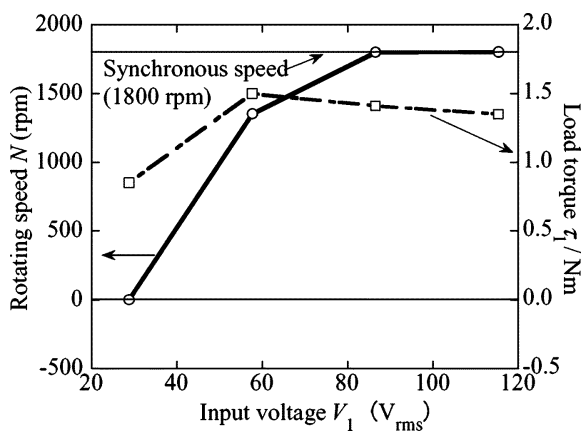

Fig. 7. Experimental results of rotating speed, $N$, vs. input voltage, $V_{1}$, characteristics with the application of light load at $77.3 \mathrm{~K}$.

\section{B. Rotating Characteristics for Different Input Voltages}

Fig. 6 shows the test results of relationship between the rotating speed, $N$, vs. input voltage, $V_{1}$. All data are obtained at steady state. As is already mentioned, the motor starts rotating at $V_{1}=22.7 \mathrm{~V}_{\mathrm{rms}}$. Further, it can be seen that the motor is swiftly pulled in to be synchronous speed (1800 rpm) just after starting.

Fig. 7 also shows the experimental results of the rotating characteristics at light load application. In case of $V_{1}=50 \mathrm{~V}_{\mathrm{rms}}$, the motor stops rotating by applying the load at $0.8 \mathrm{Nm}$. As the input voltage increases, however, the motor rotates at slip mode. Moreover, the synchronous speed is available even for the application of the load at around $1.4 \mathrm{Nm}$, when the input voltage is higher. This means that the synchronous torque exists in our fabricated HTS induction motor. This torque is impossible to be obtained for the conventional (normal conducting) induction motor, because the relative speed between the gap magnetic flux and the rotor is zero at synchronous speed. Namely, both of slip and synchronous operation is possible for the HTS induction motor.

\section{Load Test Results}

As is already mentioned, the light load can only be applied by means of the powder brake in this test system. Then, the load characteristics are obtained from the equivalent circuit (see Section III). Fig. 8 shows the calculated results of torque, $\tau$, vs. slip, $s$, curves. The curve of the conventional motor is also plotted for comparison (broken curve). As can be seen, the starting and accelerating characteristics of the HTS induction motor improve drastically compared with those of the conventional motor. That is, the maximum torque at $50 \mathrm{Nm}$ is obtained, and this value is more than 3 times larger compared with the conventional one. This indicates that special structural techniques, such as double-cage or deep slots, utilized for the conventional motor is unnecessary for obtaining adequate starting torque. Furthermore, the synchronous torque, $\tau_{\mathrm{s}}$, at about $10 \mathrm{Nm}$ is also realized. This is because of the trapping of the magnetic flux in

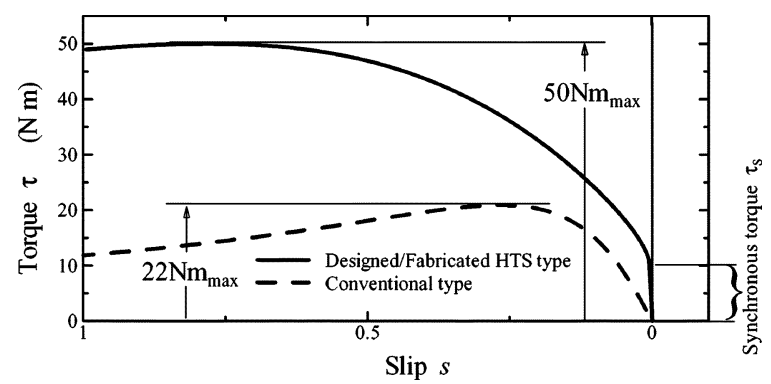

Fig. 8. Analysis result of torque, $\tau$, vs. slip, $s$, curve of HTS induction motor. The curve of the conventional motor is also obtained from the experiment.

the HTS squirrel-cage windings [see Fig. 5(b)]. In other words, the HTS induction motor is really interesting to possess larger starting torque, accelerating torque and synchronous torque.

\section{CONCLUSION}

The HTS squirrel-cage type induction motor was fabricated and tested in this study. The secondary windings were only fabricated by using the $\mathrm{Bi}-2223 / \mathrm{Ag}$ tapes, and the commercialized stator was utilized. The performance of the motor was also estimated based on the electrical equivalent circuit taking account of the nonlinear $E-J$ curve of Bi-2223/Ag tape. It was shown theoretically and experimentally that there exists the minimum voltage for starting. The HTS induction motor also had large starting as well as accelerating torque compared with the conventional motor. Furthermore, the synchronous torque was available by trapping the magnetic flux in the squirrel-cage windings.

\section{ACKNOWLEDGMENT}

T. Nakamura would like to thank Mr. Tsuneo Nakamura for supporting the experimental set-up.

\section{REFERENCES}

[1] J. Sim, M. Park, H. Lim, G. Cha, J. Ji, and J. Lee, "Test of an induction motor with HTS wire at end ring and bars," IEEE Trans. Appl. Supercond., vol. 13, no. 2, pp. 2231-2234, 2003.

[2] J. Sim, K. Lee, G. Cha, and J. Lee, "Development of a HTS squirrel cage induction motor with HTS rotor bars," IEEE Trans. Appl. Supercond., vol. 14, no. 2, pp. 916-919, 2004.

[3] G. Morita, T. Nakamura, and I. Muta, "Characteristic analysis of high $T_{\mathrm{c}}$ superconducting squirrel-cage type induction motor based on equivalent circuit," The Papers of Technical Meeting on Application of Superconductivity, IEE Japan (in Japanese) 2004, ASC-04-45, pp. 7-12.

[4] F. Irie, Y. Tsujioka, and T. Chiba, "Characteristics of critical current distributions for oxide superconductors estimated from V-I characteristics using Weibull function," Supercond. Sci. Technol., vol. 5, pp. S379-S382, 1992.

[5] T. Kiss, T. Nakamura, S. Nagano, Y. Matsumoto, F. Irie, and M. Takeo, "Critical current distribution and flux creep properties in $\mathrm{Y}_{1} \mathrm{Ba}_{2} \mathrm{Cu}_{3} \mathrm{O}_{7-\delta}$ superconducting thin films," in Advances in Superconductivity VII. Tokyo: Springer-Verlag, 1995, pp. 555-558, 1995. 